\title{
THE EFFECT OF REMAINING WATER LAYER ON FINAL TEMPERATURE OF STEEL PLATE DURING HOT ROLLING
}

\author{
Ondřej RESL, Michal POHANKA \\ Brno University of Technology, Faculty of Mechanical Engineering, Brno, Czech Republic, EU, \\ ondrej.resl@vut.cz
}

https://doi.org/10.37904/metal.2019.695

\begin{abstract}
Steel products like hot rolled steel plates or strips are widely used in industry or in other fields of human activity. Prediction and control of cooling during hot rolling are necessary to obtain the desired mechanical properties of the hot rolled steel. Spray and laminar cooling are common ways of cooling of the hot rolled strip on a runout table in many steel industries today. Disadvantage of water cooling is remaining water on the surface of the steel strip that is accumulated and forms a water layer on upper surface. Due to the presence of the water layer, jets do not impact on the steel surface directly and the cooling intensity is changed.

In this article, simulations of top and bottom cooling of the steel strip on the run-out table during hot rolling are performed using experimentally obtained boundary conditions. The experiment for obtaining boundary conditions is also described. Simulation with remaining water on the surface and simulation where the effect of the water layer was neglected are compared and the influence of the remaining water on the final temperature of the steel strip, which is an important parameter to control the quality of the final product, is investigated.
\end{abstract}

Keywords: Steel, temperature, water, cooling, heat transfer coefficient

\section{INTRODUCTION}

The hot rolled steel plates and strips are widely used in many fields of human activity. To achieve the desired mechanical and physical properties of the steel the cooling process during hot rolling must be controlled. After the steel passes through a roughing mill and a finishing mill it is cooled on a run-out table (ROT) to the final temperature at a given cooling rate. Today water spray and laminar jets are widely used for top and bottom cooling of the steel strip on the ROT. Much work has been done to improve the cooling process, but there are still problems such as low cooling efficiency, low cooling capacity or poor cooling uniformity [1]. The cooling process is influenced by many parameters like nozzle type, velocity of the steel strip, water temperature, surface temperature of the steel, remaining water on the surface or surface roughness [2-4].

Due to a large amount of water that impinges on the moving steel strip during cooling on the ROT, the surface of the steel strip is covered by water layer. The remaining water causes that jets do not impact on the steel surface directly, but impact on the accumulated water layer, and also influences the cooling intensity. Further, the remaining water causes overcooling edge [5]. The height of remaining water layer increases with increasing water flow rate density [6]. The remaining water was studied by Cho et al. [7]. They investigated the effect of strip width and flow rate on the height of remaining water layer and they developed an equation to predict the height of remaining water layer. In [8] Fujimoto et al. investigated the flow characteristics of single circular water jet impingement on a moving surface covered with a water layer. Kwon and Park [3, 6] devised a concept of artificial sidewalls to apply a realistic height of remaining water layer to numerical simulation of strip cooling.

In this study, experimentally obtained boundary conditions are used for simulations of top and bottom cooling of the steel strip on the ROT and the influence of the remaining water on the final temperature of the steel strip is investigated. 


\section{EXPERIMENT DESCRIPTION}

\subsection{Impact pressure distribution measurements}

Method with flat plate was used for the impact pressure distribution measurement. The nozzle sprays on a moving plate that is equipped with a pressure sensor with active element of $1 \mathrm{~mm}$ in a diameter (Figure 1). For a given nozzle configuration, the pressure is measured as position dependent value while the plate with the sensor is slowly moving under the spraying nozzle. Direct output from impact pressure measurement is a pressure distribution described in equidistant mesh.

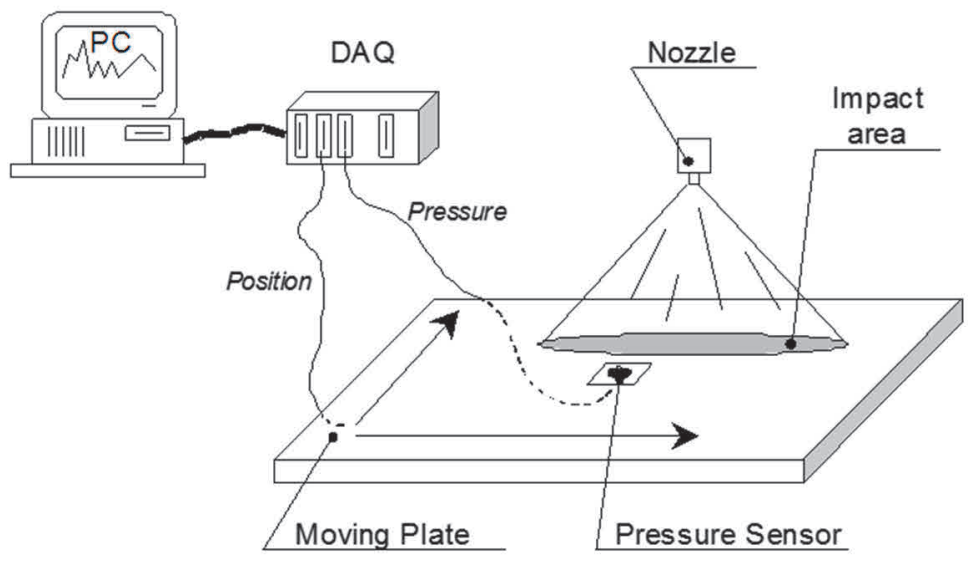

Figure 1 Scheme of experimental apparatus for impact pressure distribution measurements

\subsection{Heat transfer coefficient measurements}

Laboratory test bench with linear movement of the test plate was used for measurement of the heat transfer

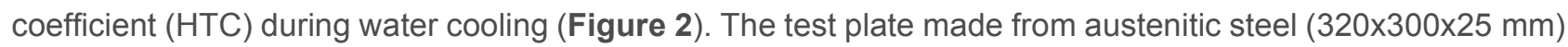
was equipped with thermocouples located $0.8 \mathrm{~mm}$ under the cooled surface. The test plate was attached to carriage and placed in electric heater. Then the test plate was placed into upper or bottom position depending on the conditions of the measurement. After that the carriage with test plate was moving repeatedly under (above) nozzles at prescribed velocity until the final temperature of cooled test plate was reached. Finally, data that included temperature history and information about test plate position according the cooling section were downloaded to computer.

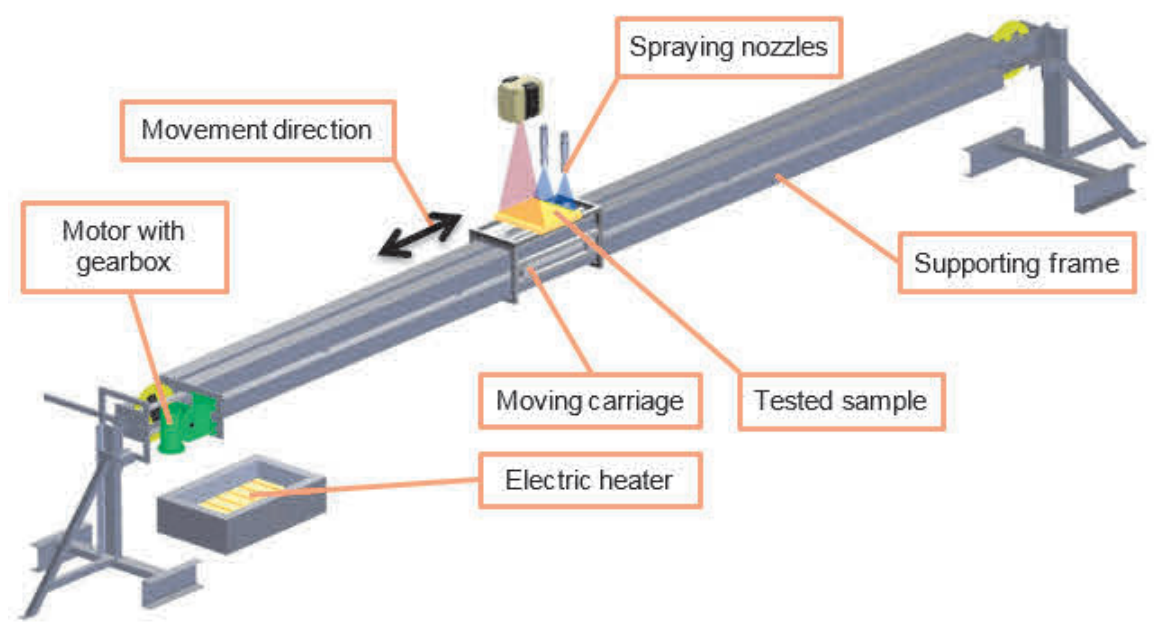

Figure 2 Experimental stand for HTC measurements 
Three nozzles in one row with nozzle pitch $200 \mathrm{~mm}$ were used for cooling during one experiment. Flat-jet nozzles with the spray angle of $30^{\circ}$ and the flow rate of $0.8 \mathrm{l} / \mathrm{s}$ at $0.1 \mathrm{MPa}$ were used for upper cooling. The spray distance was $600 \mathrm{~mm}$ to avoid collision with strip. For bottom cooling, three full-cone nozzles with the spray angle of $80^{\circ}$ and the flow rate of $0.8 \mathrm{l} / \mathrm{s}$ at $0.1 \mathrm{MPa}$ were used. The spray distance was $100 \mathrm{~mm}$.

Measured temperature history was used as input to inverse computation. The outputs from the inverse computation were time dependent HTC and time dependent surface temperature. Because the position of carriage was also recorded during measurement, the $\mathrm{HTC}$ can be evaluated as a function of carriage position and surface temperature (Figure 4 and Figure 5). The zero position in these figures is a position directly under (or above) the row of nozzles. The HTC was used as a function of carriage position and surface temperature for boundary conditions during numerical simulations of cooling of the steel strip.

\section{NUMERICAL SIMULATIONS OF STRIP COOLING}

The length of cooling for numerical simulations was $10 \mathrm{~m}$ for the final temperature of $700{ }^{\circ} \mathrm{C}$ and $14 \mathrm{~m}$ for the final temperature of $300{ }^{\circ} \mathrm{C}$. The velocity of the steel strip was $2 \mathrm{~m} / \mathrm{s}$. Required cooling intensity was approximately $100{ }^{\circ} \mathrm{C} / \mathrm{s}$. Starting temperature was $900{ }^{\circ} \mathrm{C}$ and required final temperature was $700{ }^{\circ} \mathrm{C}$ for simulation "Sim-5" and $300^{\circ} \mathrm{C}$ for simulations "Sim-10" and "Sim-11". The number in simulation name represents number of cooling sections. The pitch of cooling sections was $1 \mathrm{~m}$. Six numerical simulations were done in total (Table 1). Three with neglected effect of the water layer on the surface and three with remaining water.

Table 1 Conducted numerical simulations

\begin{tabular}{|c|c|c|c|}
\hline Simulation & Number of cooling section & Remaining water & $\begin{array}{c}\text { Final computed temperature } \\
\left({ }^{\circ} \mathrm{C}\right)\end{array}$ \\
\hline Sim-5 & 5 & No & 699 \\
\hline Sim-5-water & 5 & Yes & 677 \\
\hline Sim-10 & 10 & No & 413 \\
\hline Sim-10-water & 10 & Yes & 285 \\
\hline Sim-11 & 11 & No & 314 \\
\hline Sim-11-water & 11 & Yes & 110 \\
\hline
\end{tabular}

\section{RESULTS}

\subsection{Impact pressure distribution measurements}

Measured impact pressure distribution is shown in the Figure 3. The flat-jet nozzle which was used for top cooling is on the left side in Figure 3 and the full-cone nozzle for bottom cooling is on the right side. In the case of the top cooling the value of the maximum impact pressure is higher than in the case of the bottom cooling, because flat-jet nozzles were used instead of full-cone nozzles.

\subsection{HTC measurements}

Obtained HTC functions are shown as a function of carriage position and surface temperature in the Figure 4 and Figure 5. Data with remaining water on the surface are shown on the left side and modified data where the effect of the water layer was neglected are shown on the right side. 


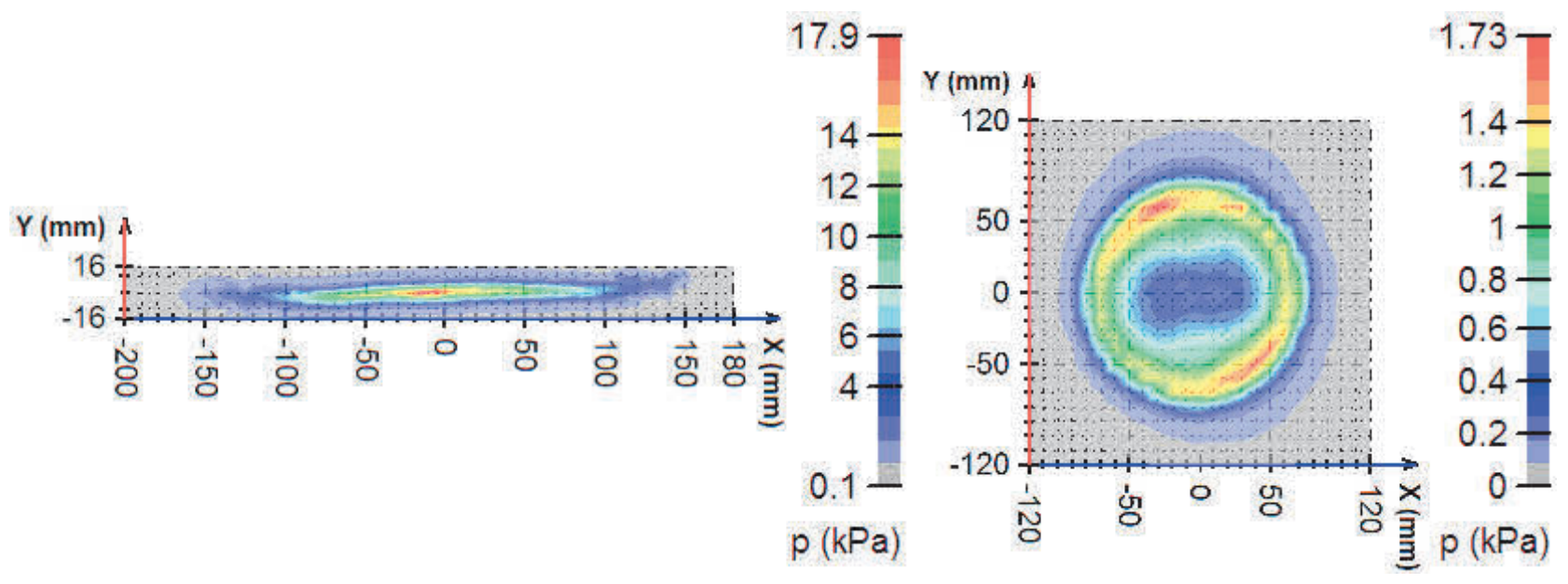

Figure 3 Measured impact pressure distribution (left graph: one flat-jet nozzle for upper cooling; right graph: one full-cone nozzle for bottom cooling)
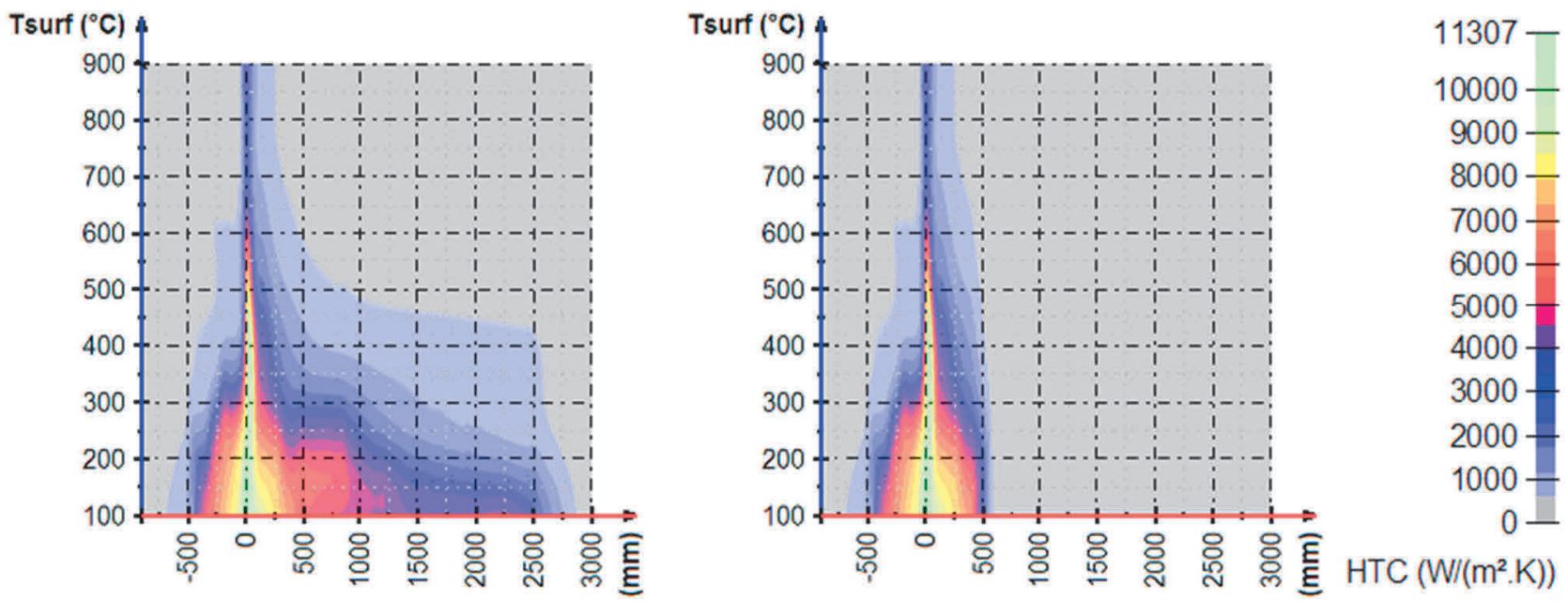

Figure 4 Top cooling - HTC as a function of carriage position and surface temperature (left graph: data with remaining water; right graph: data neglecting remaining water)
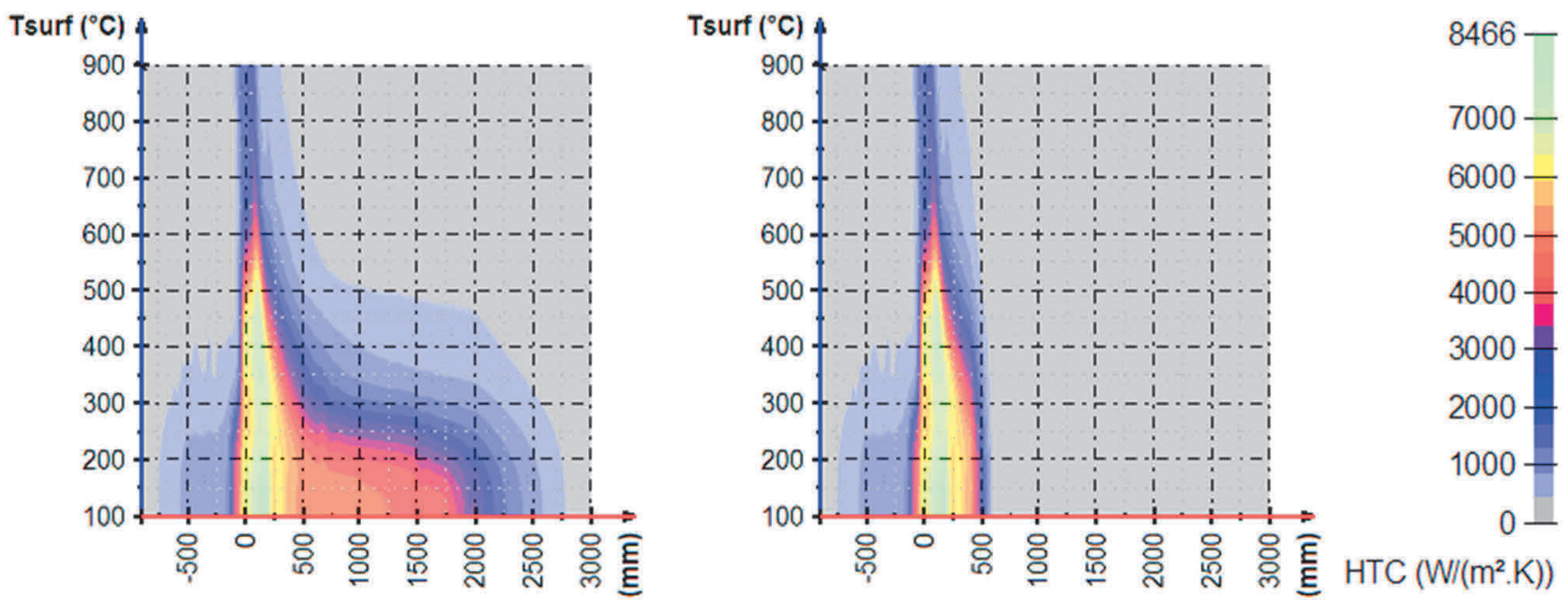

Figure 5 Bottom cooling - HTC as a function of carriage position and surface temperature (left graph: data with remaining water; right graph: data neglecting remaining water) 
It can be seen from Figure 4 and Figure $\mathbf{5}$ that the area with very high HTC near position $0 \mathrm{~mm}$ is wider in case of bottom cooling because full-cone nozzles were used for bottom cooling. It is also evident that significant cooling occurs more than $2 \mathrm{~m}$ after the cooling section due to the remaining water when the surface temperature drops below $500{ }^{\circ} \mathrm{C}$ and becomes more and more important as the surface temperature decreases.

\subsection{Numerical simulations of strip cooling}

Six numerical simulations (Table 1) of strip cooling with experimentally obtained boundary conditions (Figure 4, Figure 5) were done. Detail of computed temperatures using numerical simulation "Sim-10-water" and used HTC are shown in the Figure 6. Top and bottom cooling are slightly different in time, but the total cooling is very similar. Temperatures on the top and bottom surface are slightly lower than the temperature in the center of the test plate before the strip enters the cooling section.

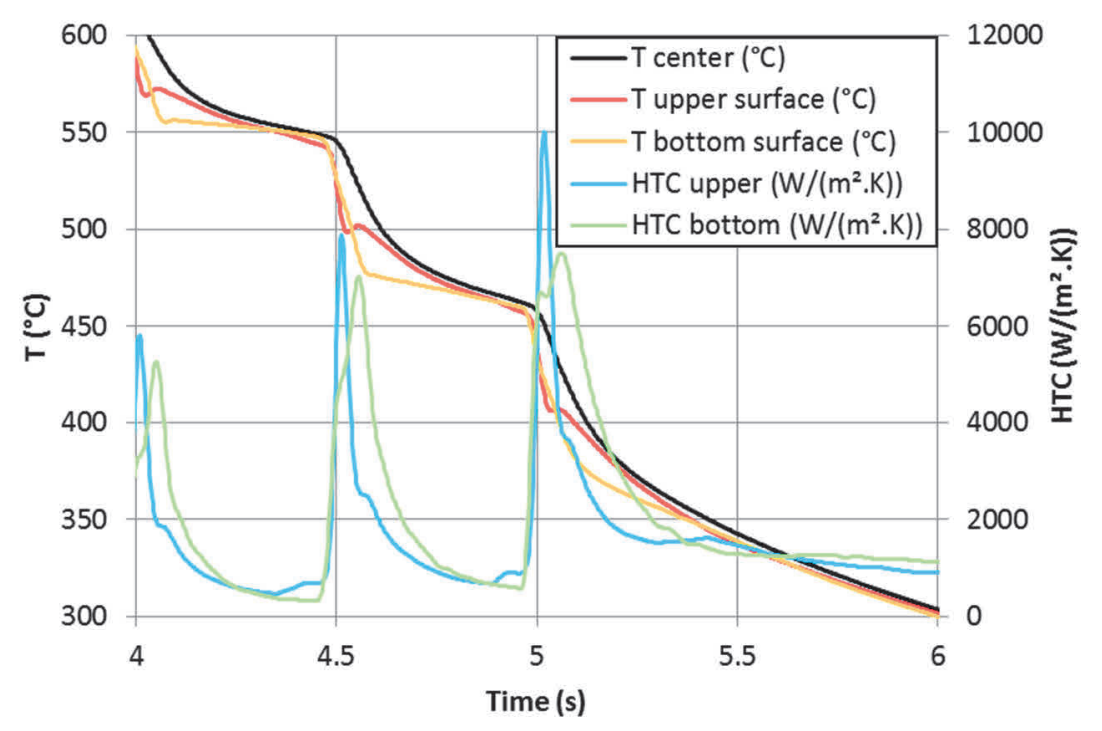

Figure 6 Detail from numerical simulation "Sim-10-water" and applied HTC
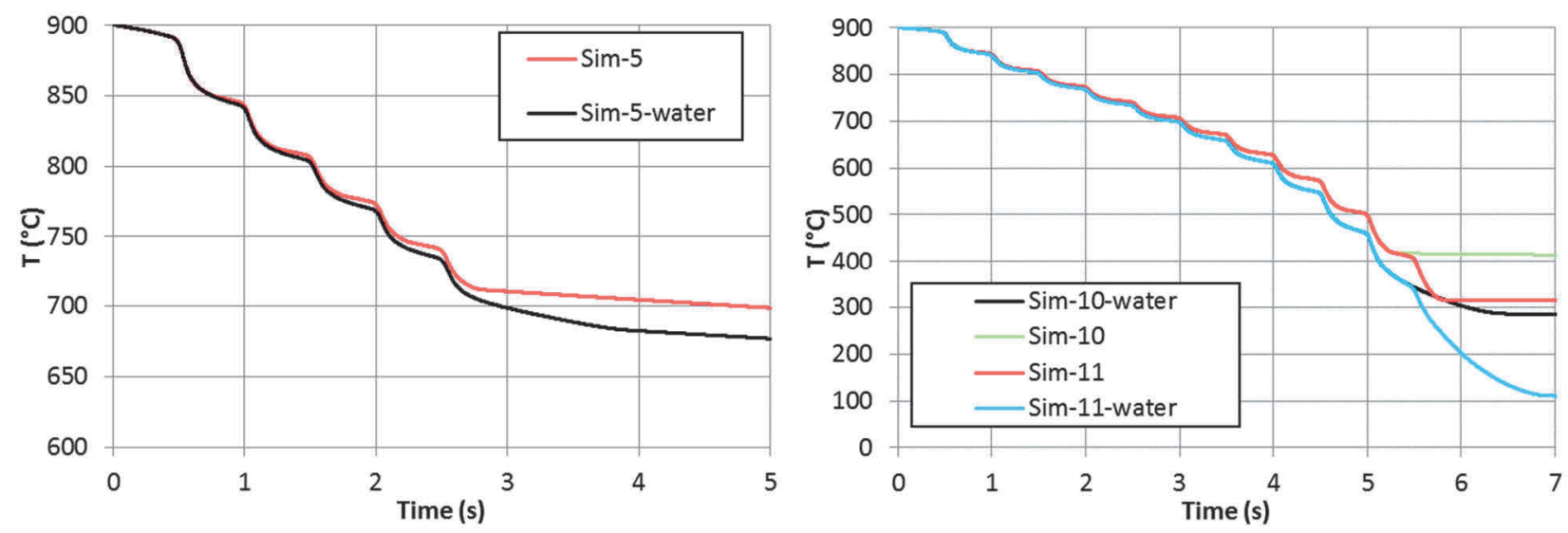

Figure 7 Conducted numerical simulations (left graph: the final temperature of $700{ }^{\circ} \mathrm{C}$; right graph: the final temperature of $300^{\circ} \mathrm{C}$ )

Results from all conducted numerical simulations are compared in the Figure 7. In a high temperature region, the difference between simulation with neglected water layer on the surface "Sim-5"' and simulation with remaining water "Sim-5-water" is minimal. The temperature difference is $12^{\circ} \mathrm{C}$ at the time of $3 \mathrm{~s}$ and $22{ }^{\circ} \mathrm{C}$ at 
the time of $5 \mathrm{~s}$. A different situation occurs if the required final temperature is $300{ }^{\circ} \mathrm{C}$. The correct number of cooling sections is 10 ("Sim-10-water") and the final temperature is $285^{\circ} \mathrm{C}$ in this case. If data with neglected water layer are used, the computed final temperature using "Sim-10" is $413^{\circ} \mathrm{C}$ which is too high. If we want to reach the required final temperature and we do not consider the influence of remaining water, we have to add another cooling section. Simulation "Sim-11" with one more cooling section (11 cooling sections in total) gives nice final temperature $314{ }^{\circ} \mathrm{C}$. However, when correct $\mathrm{HTC}$ with remaining water effect is used for numerical simulation the final temperature is only $110^{\circ} \mathrm{C}$ which is $190^{\circ} \mathrm{C}$ below target temperature. Thus, the influence of remaining water layer becomes very important when the final temperature is below $500{ }^{\circ} \mathrm{C}$.

\section{CONCLUSION}

Numerical simulations of strip cooling with experimentally obtained boundary conditions were done and influence of the remaining water layer on the final temperature of steel strip was investigated. HTC, which was used as a boundary condition for numerical simulations, was measured for top and bottom cooling. Impact pressure distribution measurements of water sprays from nozzles used in experiment were done.

It was found that the remaining water layer has a big influence on final temperature when the target temperature is below $500{ }^{\circ} \mathrm{C}$. If the effect of remaining water layer was neglected, the simulation showed final temperature of steel strip $314{ }^{\circ} \mathrm{C}$. The difference from real final temperature (cooling with the effect of remaining water) was $204^{\circ} \mathrm{C}$. Similar behavior was confirmed by steel producer. This big difference will cause distinct properties of the steel strip and it will lead to worse quality. The remaining water has to be considered and removed properly from the strip surface to avoid problem with final temperature of the steel.

\section{ACKNOWLEDGEMENTS}

\section{The paper presented has been supported by the internal grant of the Brno University of Technology focused on specific research and development No. FSI-S-17-4346.}

\section{REFERENCES}

[1] XIE, Qian, HUANG, Zhenyi, HOU, Qingyu, ZHANG, Long and CAI, Jiajia. Heat Transfer from a Hot Steel Plate Impinged by Air-atomized Water Jet and Impinging Water Jet. ISIJ International. 2019. vol. 59, no. 1, pp. 113-121.

[2] CHEN, Shih-Jiun and TSENG, Ampere A. Spray and jet cooling in steel rolling. International Journal of Heat and Fluid Flow. 1992. vol. 13, no. 4, pp. 358-369.

[3] KWON, Myeon Jae and PARK, II Seouk. Numerical Simulation of Cooling Process after Hot Rolling with Realistic Residual Water Levels. ISIJ International. 2015. vol. 55, no. 8, pp. 1791-1793.

[4] BROŽOVÁ, T., CHABIČOVSKÝ, M. and HORSKÝ, J. Influence of the surface roughness on the cooling intensity during spray cooling. In METAL 2016: 25rd International Conference on Metallurgy and Materials. Ostrava: TANGER, 2016, pp. 41-46.

[5] WU, Wei-Lin, WANG, Wei-Cheng and LO, Wei. The study of improving the strip flatness in run-out-table during laminar cooling. The International Journal of Advanced Manufacturing Technology. 2018. vol. 95, no. 12, pp. 4419-4437.

[6] KWON, Myeon Jae and PARK, II Seouk. Hydrodynamic Investigation to Reflect Actual Residual Water Levels in Simulation of Strip Cooling after Hot Rolling. ISIJ International. 2014. vol. 54, no. 12, pp. 2936-2938.

[7] CHO, Myung Jong, THOMAS, Brian G. and LEE, Pil Jong. Three-Dimensional Numerical Study of Impinging Water Jets in Runout Table Cooling Processes. Metallurgical and Materials Transactions B. 2008. vol. 39, no. 4, pp. 593-602.

[8] FUJIMOTO, Hitoshi, SUZUKI, Yuhei, HAMA, Takayuki and TAKUDA, Hirohiko. Flow Characteristics of Circular Liquid Jet Impinging on a Moving Surface Covered with a Water Film. ISIJ International. 2011. vol. 51, no. 9, pp. 1497-1505. 